\title{
Dietetic intervention required to cardiac medical and surgical wards at a teaching hospital
}

\author{
C. O’Flynn, O. Hamer and S. Burden \\ Manchester Royal Infirmary, Oxford Road, Manchester M13 9WL, UK
}

Amongst patients with CVD there is strong acknowledgement that the cardioprotective diet plays an important role in long-term care ${ }^{(1)}$. The prevalence of malnutrition amongst patients with CVD is, however, not widely recognised.

The present audit reviewed all inpatients on cardiac wards on dietetic referrals over 1 year. A total of 194 patients were included (120 males and seventy-four females; mean age 68 (range 16-90) years). Nutritional status, anthropometry, reason for referral, length of time under the care of the dietitian and follow-up requirements were recorded.

Table 1. Referral to dietitian according to cardiac operation

\begin{tabular}{lccc}
\hline & Table 1. Referral to dietitian according to cardiac operation & \multicolumn{2}{c}{ Patients referred to dietetic service } \\
\cline { 2 - 4 } Cardiac operation & $\begin{array}{c}\text { Operations }(n) \\
\text { October }\end{array}$ & $n$ & \multicolumn{2}{c}{ 2005-September 2006 } \\
\hline Coronary artery bypass grafts & 460 & 45 & 10 \\
Valve replacements & 201 & 36 & 18 \\
Combined operations & 113 & 10 & 9 \\
\hline
\end{tabular}

Table 2. Anthropometric measurements undertaken

\begin{tabular}{lrr}
\hline & & Patients \\
\cline { 2 - 3 } Anthropometry & $n$ & 139 \\
\hline Recorded BMI & 29 & 81 \\
BMI $<20 \mathrm{~kg} / \mathrm{m}^{2}$ & 65 & 21 \\
Weight losing & 35 & 38 \\
Weight loss $>10 \%$ or weight loss $>5 \%$ and BMI $<20 \mathrm{~kg} / \mathrm{m}^{2}$ & 20 \\
\hline
\end{tabular}

Nutritional support intervention was given to 149 patients $(77 \%)$; $100(52 \%)$ of patients required oral nutrition support and forty-nine $(25 \%)$ required enteral feeding. Healthy eating advice was given to fourteen (7\%) patients. Over one-third of patients were weight losing and $20 \%$ were malnourished using the National Institute for Health and Clinical Excellence criteria ${ }^{(2)}$. The majority of patients (ninetyone; $47 \%)$ were under dietetic management for $<10 \mathrm{~d}$, thirty-four $(18 \%)$ were seen for $>1$ month and fifty-three $(29 \%)$ patients required continued dietetic support on discharge.

The number of patients referred to the dietitian for nutritional support was higher than the ward expected, although malnutrition in patients on medical and surgical cardiac wards was potentially underestimated given the amount of total clinical activity. This audit demonstrates that healthy eating advice is not always the priority for patients on cardiac wards. The malnutrition universal screening tool has now been implemented to help identify all patients who require nutritional support intervention ${ }^{(3)}$.

1. UK Heart Health and Thoracic Dietitians Interest Group (2006) J Hum Nutr 19, 401-419.

2. National Institute for Clinical Health and Excellence (2006) Nutrition support in adults: oral nutrition support, enteral tube feeding, parenteral nutrition. http://www.nice.org.uk/nicemedia/pdf/cg032fullguidelineappendices.pdf

3. British Association for Parenteral and Enteral Nutrition (2003) Malnutrition Universal Screening Tool. http://www.bapen.org.uk/pdfs/must/must_ full.pdf 